\title{
Research on the development and application of museum cultural Resources display based on virtual reality technology
}

\author{
Wang Yulie ${ }^{1, a}$, Sun Yujie ${ }^{1, b}$, Zhou Chongwu ${ }^{1, c}$ \\ ${ }^{1}$ School of Design and Art Shenyang Aerospace University Shenyang, Liaoning
}

\begin{abstract}
The development of museum cultural industry, as the key content of the development of national cultural industry, affects the inheritance of national culture and history. Due to the constant update of hightech, new media and other technologies, the display of cultural resources in museums is becoming more and more diversified. The application of virtual reality technology, digital interaction technology, new media and other technologies brings new vitality to the display design of modern museums. Under the background of this era, the exhibition of museum cultural resources is researched and explored. At present, virtual reality technology is gradually applied in the display and dissemination of cultural resources. This paper discusses how to realize the application of this technology in the display of cultural resources in museums.
\end{abstract}

\section{ANALYSIS OF THE CURRENT SITUATION OF MUSEUMS IN CHINA}

With the development of social culture, science and technology, the number and types of museums are increasing. Museums are places that represent the natural and human cultural heritage, as well as places that provide the public with knowledge, education and other cultural resources. However, the exhibition form of museum cultural resources in China is in a bottleneck period, and the combination of simple technology and equipment cannot meet the needs of the public. The application of virtual reality technology effectively enhances the communication effect of museum cultural resources and greatly improves the communication effect of museum exhibitions.

\subsection{Current status of museums}

Most of the existing museums in China are created by the government or the country. Due to the rapid development of the era of science and technology, the construction of museums has formed a trend of rapid development, with more and more visitors, and the form of exhibition is gradually changing.

1.1.1 Museums are a symbol of a country's civilization and social progress, and a reflection of the comprehensive strength of a city and the region it represents in terms of science, technology, culture and resources. With the development of economy and the continuous improvement of people's living standards, people's cultural quality is gradually improved, and their spiritual and cultural needs are also growing day by day. Visiting museums has become an increasingly important part of people's life. But the traditional way of visiting museums cannot meet the psychological needs of the public.

1.1.2 At present, the museum exhibition exhibition pay attention to experience and interactive, engaging experience and the interaction of the earliest display all kinds of science and technology museum, this way not only on the display content close to the visitor's life, also through the communication with visitors on many aspects, spreading culture resources, show the latest science and technology.

\subsection{Existing problems of the museum}

With the increase in the number of museums, the museum has not achieved a stable development due to the lack of experience, talent, lack of funds and other reasons. The progress of science and technology has made the museum make significant progress, but the demonstration problems still exist, which are mainly reflected in the following aspects:

1.2.1Museums are for the purpose of displaying and promoting cultural and intellectual places to the audience. According to the data of the Ministry of Culture and Tourism, the scale of Museums in China increased rapidly year by year from 1996 to 2017, with an annual compound growth rate of $6.6 \%$. However, in the absence of software and hardware equipment, lack of experience, lack of talent, resulting in a relatively backward display form, display content and techniques, the overall stage of extensive development, compared with some developed countries,

\footnotetext{
amaxyule@sina.com

b835563598@qq.com

c1061674964@qq.com
} 
there is a large gap. No matter from the hardware equipment of the museum or the ideas and concepts of the management, they have not kept pace with the development and changes of The Times and cannot meet the needs of current visitors.

1.2.2 Museums without its own characteristics is a kind of common phenomenon, homogeneity, the present situation of the "thousand pavilion side" extremely serious, can't interested visitors to watch, watch is also in the process of the state of the tour, make visitors to produce aesthetic fatigue, difficult to arouse desire, visitors lose interest in the museum.

1.2.3 The limited number of museum exhibits on display, cannot make full use of cultural resources supply visitors, lay a large number of cultural relics in the storehouse "falls asleep", visitors happy display is too little, the museum cultural products can't meet the spiritual needs of the broad masses of the people, at the same time, the application of modern science and technology means less, even if there are some interactive device products, experience the effect is not obvious. It is counterproductive to affect visitors' sense of immersion experience.

\section{VIRTUAL REALITY TECHNOLOGY AND THE DISPLAY AND APPLICATION OF CULTURAL RESOURCES IN MUSEUMS}

\subsection{Virtual reality technology}

Virtual reality technology is a combination of simulation technology and computer graphics, human-computer interaction technology, multimedia technology, sensing technology, network technology and other technologies. It is a challenging interdisciplinary frontier science and research field. Is a can create and experience the virtual world of computer simulation system, which USES computer to generate a simulation environment, is a kind of multi-source information fusion, interactive $3 \mathrm{~d}$ dynamic visual and physical behavior of the system simulation, and immersed in the environment, the users get the stimulation of touch, taste, smell, etc, to produce a resonance.

\subsection{Ways of displaying museum cultural resources}

\subsubsection{Traditional exhibition mode in the museum}

In offline Space Museum exhibition venues, the most common form of the museum exhibition culture resources are the most traditional, based on the exhibition exhibits in kind as its carrier, visitors can only passive accept the visit to browse, visitors and interactive form of exhibits are limited to "watch", the traditional way is dependent on the material entity. The cultural relics in the museum belong to the national collection. During the exhibition process, there are restrictions on the wear, repair and future development of the exhibits in the museum, which cannot meet the more psychological needs of visitors.

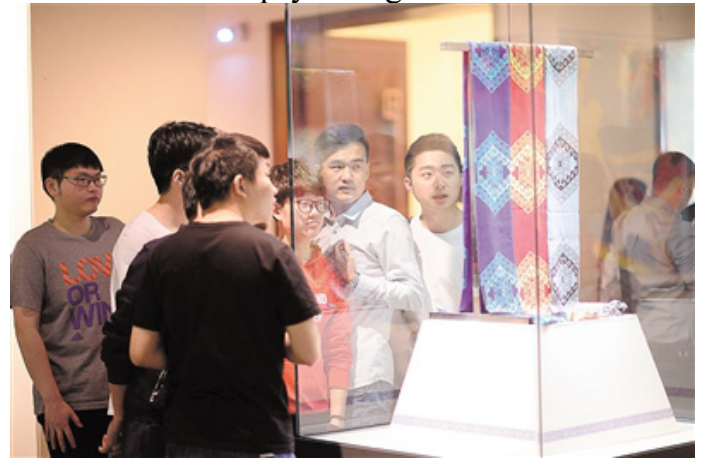

Figure 1: Traditional exhibition mode in the museum

\subsubsection{Multimedia display mode}

With the advent of the era of network, science and technology, the museum cultural resources to produce a new display, multimedia projection, using multimedia transmission demonstration to traditional voice, text and images through computer data processing, transfer to the screen, this innovative way is just to innovation of information media, did not bring visitors impressed, adopt the majority of small and medium-sized museum display of digital culture resources.

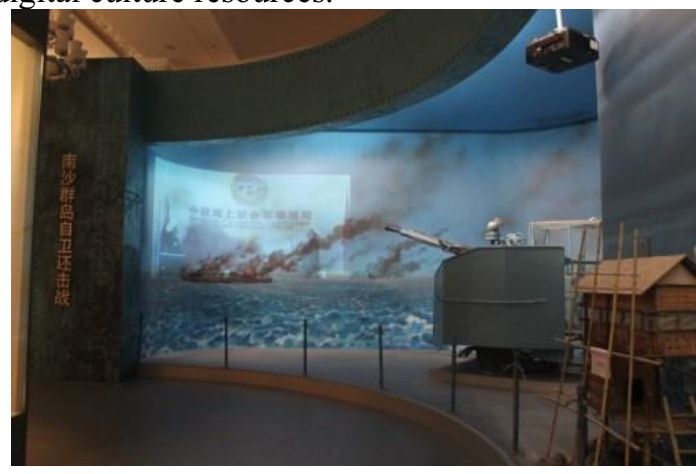

Figure 2: Multimedia display mode

\subsubsection{Virtual museum display}

In recent years, the generation of virtual reality technology, which is popular all over the world, plays an important role in the dissemination and development of Traditional Chinese cultural resources. Relying on modern scientific and technological means, it enables visitors to create and design feelings of experiencing virtual scenes in a specific scope. Even offline entities museum visitors don't need to be quick and easy to browse museum exhibits information of cultural resources, and virtual reality technology also can reflect more the embassy exhibits cultural regeneration value, restore its original state, at present our country many offline museums are opened in the corresponding online virtual museum. 


\section{THE APPLICATION OF VIRTUAL REALITY TECHNOLOGY TO DISPLAY FEATURES OF MUSEUM CULTURAL RESOURCES}

With the development of the society, the museum has become more and more modern, and the way of visiting the visitors has also undergone great changes. For example, the Capital Museum of Beijing USES virtual reality technology to truly restore the site of tomb excavation, and through excavating unearthed cultural relics, it restores the ancient bustling market thousands of years ago. The British Museum has built its own digital museum through computer technology and virtual reality technology. Visitors from all over the world can view the information of cultural relics of the British Museum through online cloud browsing. Will effectively by using virtual reality technology, museum exhibits the cultural resources in a variety of display mode is presented to visitors, the limited museum entity space to rise to the virtual scene, the visitors in the virtual space of multidimensional experience that visitors have a "real" experience, the experience is "immersion" or the "inputs", meet the demand of visitors viewing, effectively solve the oneness cultural resources at the museum, further to careful observation of the museum's collection and understanding, meet visitors spiritual pursuit and the understanding of cultural resources.

\subsection{Improvement of visitors' active participation}

In the traditional museum design, a single message is usually conveyed. The exhibits in the museum are passively received by visitors through images, words and sounds, and lack of active participation by visitors. Through the application of virtual reality technology, the museum is digitized. With helmets, handles and other hardware devices, visitors are encouraged to take the initiative to participate in the exhibition projects, and visitors are attracted to take the initiative to understand and explore the knowledge of historical relics. The technological and intelligent interactive form enables visitors to have more psychological activities and generate indescribable emotion for the museum's cultural resources, which is much more interesting than the cursory sightseeing. This will change the one-way exhibition in the museum and is also the general trend of museum display design under the development of The Times.

\subsection{Improvement of visitors' experience and interaction}

Virtual reality technology design of the museum of cultural relics show, totally broke the traditional "do not touch" form of museum in the past, visitors through the combination of hardware, software, equipment, information for the museum of cultural relics, let visitors to participate in the form of their own experience, vivid sensory stimulation and the formation of natural interaction feedback, constitutes a immersed sexual experience. Visitors interact with cultural relics in more innovative forms and leave a deeper impression on visitors. Such interaction is not limited to simple physical interaction, but can also include emotional interaction. Visitors have subjective initiative.

\subsection{Improvement of museum entertainment}

Under the virtual reality technology, the digital museum has a rich form of expression for the museum's cultural relics. Most of the applied technologies are virtual display. The museum's cultural relics are displayed by means of science and technology through simulation. In the process of exhibition, various ideas are integrated and various means are used to realize things that cannot be directly presented in the traditional way, so that the static museum display can get rid of the boring state and make it full of entertainment.

\section{CONCLUSION}

Chinese culture is extensive and profound, and China's cultural heritage is also extremely rich. In recent years, the Chinese government attaches great importance to the display of cultural resources in museums. The construction of museums in China is still in the exploratory stage, and the single display of traditional museums no longer meets the needs of the public. With the continuous development of virtual reality technology, the application of virtual reality technology to museums can make better use of the power of science and technology, combine technology with culture, constantly promote the development of cultural resources of museums, attract more visitors, and create a cultural prospect with far-reaching influence.

\section{ACKNOWLEDGMENTS}

Thank you for the support of the college and the guidance of the tutor, and I took time to review and revise my thesis during my busy teaching work. There are also teachers who have taught me. Your rigorous and serious style is a role model for me in my study and work; their persuasive teaching and meticulous thinking have given me endless enlightenment. At the same time, I would like to thank my classmates and friends for their valuable comments. With their support, I can finish writing on time.

At the same time, this research was supported and approved by the Social Science Foundation of Liaoning Province (No. L17BKG002).

\section{REFERENCES}

1. Yue Dingcong. Research on interactive experience of museum digital display[D]. Shenzhen University, 2018.

2. Wang Yulie, Su Xin, Tian Hao. The narrative display and experience research of virtual reality in the ruins museum[J]. Journal of Nanjing University of the Arts (Fine Arts and Design),2019(03):199-201.

3. Wang Shengjie. Application research of virtual reality 
technology in museum display design[D]. Jiangnan University, 2018.

4. Tan Yuanyuan. The application prospects of augmented reality technology in the design of cultural relics in small and medium museums[J].Knowledge Guide,2014(09):135-136.

5. Zhang Yingying, Shi Xiping, Qin Jingyan. Serviceoriented museum sustainable experience design research $[\mathrm{J}]$.Packaging Engineering,2015,36(22):1$4+12$. 